\title{
Intestinal Microbiota of Patients with Bacterial Infection of the Respiratory Tract Treated with Amoxicillin
}

\author{
Maria Tereza Ferreira Duenhas Monreal', \\ Paulo Câmara Marques Pereira ${ }^{2}$ and \\ Carlos Alberto de Magalhães Lopes ${ }^{2}$
}

\author{
${ }^{1}$ Federal University of Mato Grosso do Sul (UFMS), \\ Campo Grande, MS; ${ }^{2}$ State University of São Paulo \\ (UNESP); Botucatu, SP, Brazil
}

\begin{abstract}
The intestinal tract harbors a huge diversity of metabolically-active aerobic and anaerobic bacteria that interact, forming a complex ecosystem. This microbiota has an important role in human metabolism, nutrition, immunity, and protection against colonization by pathogenic microorganisms. Several factors can influence the intestinal microbiota; these include age, diet, inflammatory and infectious processes, and the use of antimicrobials. We investigated the influence of bacterial infection of the respiratory tract and of amoxicillin therapy on the normal intestinal microbiota of patients. Bacterial infectious processes affecting the respiratory tract were found to influence the intestinal microbiota, significantly decreasing the number of colony-forming units (CFUs) of Bacteroides spp. and Lactobacillus spp. per gram of feces. The use of amoxicillin also influenced the intestinal microbiota, significantly decreasing the CFU of Bifidobacterium spp. and Lactobacillus spp. /g of feces. Changes in the composition of the intestinal microbiota need to be observed, since a decrease in the normal microorganisms can pose a number of hazards for hosts, including decreased resistance to colonization. With proper follow-up, health-care teams can minimize such hazards by implementing suitable therapy- and diet-related measures, thus reducing the occurrence of detrimental effects on the gastrointestinal ecosystem.

Key Words: Intestinal microbiota, bifidobacterium, bacteroides, lactobacillus.
\end{abstract}

The gastrointestinal tract harbors a huge diversity of aerobic and anaerobic bacteria that interact in a complex ecosystem [1]. This microflora comprises 400 to 500 metabolically-active bacterial species, which have a pronounced impact on the host's intestinal function and health $[2,3]$. There is evidence that the dominant profile of anaerobic bacteria usually found in adults is established in the first four years of life [4].

Overall, intestinal bacteria can be grouped into species that have detrimental effects on the host and species that have beneficial effects. The detrimental effects include diarrhea, infections, liver damage, carcinogenesis, and intestinal putrefaction. Inhibition of

Received on 25 February 2005; revised 12 June 2005.

Address for correspondence: Dr. Maria Tereza Ferreira Duenhas Monreal. Rua Dr. Armando da Cunha, 471, Campo Grande, MS 79051-040, Brazil. E-mail: monreal@brturbo.com.

The Brazilian Journal of Infectious Diseases 2005;9(3):292-300 (C) 2005 by The Brazilian Journal of Infectious Diseases and Contexto Publishing. All rights reserved. harmful bacteria (a mechanism known as 'resistance to colonization') [5], stimulation of the immune system, improvements in the digestion and absorption of essential nutrients, and vitamin synthesis are examples of the protective effects brought about by the intestinal microbiota [6]. The normal microbiota acts as a barrier, preventing colonization by potentially pathogenic microorganisms and an overgrowth of microorganisms that are already present, such as yeasts, which can cause systemic infections in immunodepressed patients, and Clostridium difficile, which can be a cause of diarrhea and pseudomembranous colitis [7,8].

Microorganisms of the genera Bifidobacterium and Lactobacillus perform a variety of functions important for the host's health. Whereas microorganisms of the genus Bacteroides have beneficial as well as detrimental effects [9], those of the genus Lactobacillus contribute to sustaining resistance to colonization, possibly by producing acetic and lactic acids, which lower intestinal $\mathrm{pH}$, thus preventing overgrowth of many potentially 
pathogenic microorganisms, whose spread is curbed by intestinal acidity. Lactobacillus spp. also produce hydrogen peroxide, which prevents the development of yeasts (Candida albicans) [10]. In addition, they can stimulate cells of the immune system, inducing the production of IL-12 by mononuclear cells of the peripheral blood [11]. They are also capable of converting cholesterol into coprostanol, which, being less soluble, can be excreted; this mechanism precludes its absorption and consequential increase in plasma [12]. Lactobacillus spp. and Bifidobacterium spp., when administered in food items known as probiotics [13-15], can survive the transit through the gastrointestinal tract and temporarily settle in the intestine [6], with a number of desirable effects on theimmune system, such as stimulation of phagocytic function [16] and control of the balance of pro- and antiinflammatory cytokines [15]. Bifidobacteria constitute a numerically-important group that is capable of a wide variety of biological activities important for host health. One of these activities is an inhibitory effect against other species, often preventing colonization by invasive pathogens $[17,18]$. It has been suggested that the inhibitory mechanism is related to the production of acetic and lactic acids and other wide-spectrum antimicrobial compounds [19]. In fact, microorganisms of the genus Bacteroides are nutritionally versatile, being able to use a wide range of carbon sources. They are responsible for most of the digestion of polysaccharides that takes place in the large intestine [20,21]. Like bifidobacteria, Bacteroides spp. play an important function in the mechanism of resistance to colonization by $C$. difficile [22]; they are found in large numbers in the large intestine [23].

Although the intestinal microflora remains relatively stable throughout life [8], factors such as disease and certain drugs can affect this balance [17]. This ecosystem can also be influenced by diet, geographical location, and gastrointestinal surgery [24]. Over the past years, studies have revealed the importance and participation of the intestinal microbiota in pathological processes, such as rheumatoid arthritis and atopic diseases [25-30].

Infections in the respiratory tract have also attracted the attention of investigators, as these infections are commonly seen in general clinical practice. Although antibiotics are routinely prescribed to treat such episodes, one result of antimicrobial therapy may be a reduction in the number of microorganisms that normally live in the gastrointestinal tract, which allows for an overgrowth of bacterial species that are already present and consequent colonization by potentially-pathogenic microorganisms [31].

Amoxicillin (aminopenicillin) is the drug of first choice for the treatment of respiratory tract infections. This beta-lactam antibiotic with bactericidal action is widely prescribed in clinical practice, particularly when a patient's airways are compromised [32].

Knowledge on the influence of infectious processes and antimicrobial agents on the gastrointestinal ecosystem is highly important clinically, since this microbiota has functions that affect host health. We investigated the influence of respiratory tract infections and of amoxicillin therapy on the normal intestinal microbiota of patients.

\section{Materials and Methods}

\section{$\underline{\text { Subjects }}$}

A prospective study was carried out on 42 individuals distributed into two Groups:

Group 1 (G1): 22 patients with bacterial infections of the respiratory tract (sinusitis, pneumonia), of both sexes, 19 to 50 years old, seen at the emergency department of the Hospital das Clínicas of the School of Medicine of the Universidade Estadual Paulista (UNESP) in Botucatu, SP, Brazil, from July to December 2002.

Control Group (CG): 20 blood donors of both sexes, 18 to 50 years old, screened at the blood center of the same institution over the same period.

\section{$\underline{\text { Methods }}$}

Criteria for inclusion: patients of both sexes, aged 18 years and over, with epidemiological, clinical, and imaging diagnosis of acute bacterial infectious diseases of the respiratory tract. 
Criteria for exclusion: pregnancy; lactation; women with hormonal disorders; individuals with other underlying diseases; use of medication, particularly antimicrobials, within the past 30 days.

The diagnoses of infection with bacterial microorganisms were based on clinical and epidemiological data and on nonspecific supplementary exams (complete blood counts, chest and/or sinus radiographs). Blood counts revealing leukocytosis and radiographic tests showing sinus opacity (sinusitis cases) and/or revealing lung condensation (pneumonia cases) were considered indicative of bacterial infection. Age and sex data were also recorded.

The nutritional assessment took into account dietary aspects and anthropometric measurements (weight and height). Three-day intake records were used for food intake assessment. The calculations of total calories, carbohydrates, proteins, lipids, and other specific nutrients ingested were performed with the program Virtual Nutri [33]. In each group, the nutritional classification was based on body mass index (BMI) [34].

The intestinal bacterial microbiota was assessed with the method proposed by Sutter et al. [35], with adaptations. Stool samples were collected from both groups in sterile containers with Transbac transport medium (Probac). The interval between sample collection and laboratory handling did not exceed $1 \mathrm{~h}$ [36,37]. Three stool samples were collected from patients in Group 1: before treatment (time point $\mathrm{T}_{1}$ ), at the end of treatment (time point $\mathrm{T}_{2}$ ), and 30 days after treatment (time point $\mathrm{T}_{3}$ ). Only one sample was collected from each individual in the control group (time point $\mathrm{T}_{0}$ ). A 1-g aliquot was taken from each sample and transferred into a screw-capped test tube containing $9 \mathrm{~mL}$ of Stuart transport medium (Oxoid). After homogenization, successive dilutions up to $10^{-8}$ were prepared using the same eluent. Kanamycinvancomycin blood agar, Bifidobacterium medium, and Lactobacillus selective medium (Probac) were the selective culture media used for microorganisms of the genera Bacteroides, Bifidobacterium, and Lactobacillus, respectively. Once inoculated and identified, the plates were placed into GasPak anaerobic jars (Permution) and incubated at $37^{\circ} \mathrm{C}$ for $48 \mathrm{~h}$ in a low-oxygen and high-carbon dioxide atmosphere generated by an Anaerobac system (Probac). After that, the plates were evaluated for bacterial growth and colony aspect. Colony-forming units (CFUs) were counted for each plate, and the mean values for each type of microorganism were calculated. Microorganism concentration was expressed as $\log _{10} \mathrm{CFU} / \mathrm{g}$ of feces. Observations related to colony morphology, Gram staining, and catalase testing were recorded for each plate.

Mean values and standard deviations of logtransformed data and mean values at the original scale were calculated for Bacteroides, Bifidobacterium, and Lactobacillus counts [38]. Time points $\mathrm{T}_{1}, \mathrm{~T}_{2}$, and $\mathrm{T}_{3}$ (Group 1) were compared by using Friedman's nonparametric test with calculations of $\chi^{2}$ and $p$ statistics. Comparisons of both groups at each time point were performed with the $t$-test for two independent samples (using log-transformed counts) with calculations of $t$ and $p$ statistics and/or MannWhitney's nonparametric method. The comparisons were considered significant whenever $\mathrm{p} \leq 0.05$.

The study was approved by the Research Ethics Committee of Hospital das Clínicas of the School of Medicine of UNESP in Botucatu.

\section{Results}

The distribution of subjects by sex was homogeneous in both groups (50\% males and 50\% females). In the control group. there was predominance of the 41 to 50 year (45\%) and 21 to 30 year $(30 \%)$ age ranges, whereas in Group 1 the 21 to 30 year (40\%) and 41 to 50 year $(30 \%)$ ranges predominated.

In both groups, eutrophic individuals $(\mathrm{BMI}=18.5$ to 24.9) were the most frequent. The food consumption records did not reveal significant differences between the groups in terms of macronutrients, fibers, or micronutrients.

The concentration of Bacteroides spp. in Group 1 was significantly $(\mathrm{p}<0.05)$ smaller at $\mathrm{T}_{1}$. When each experimental time point $\left(\mathrm{T}_{1}, \mathrm{~T}_{2}, \mathrm{~T}_{3}\right)$ in Group 1 was 
compared with $\mathrm{T}_{0}$ of the controls, a significant $(\mathrm{p}<0.05)$ decrease was found in the CFU of Bacteroides spp. /g of feces at $\mathrm{T}_{1}$, demonstrating that the infectious process affecting the respiratory tract of patients influenced their intestinal microorganism populations (Table 1).

The concentration of Bifidobacterium spp. in Group 1 significantly $(\mathrm{p}<0.01)$ decreased at $\mathrm{T}_{2}$. When each experimental time point $\left(\mathrm{T}_{1}, \mathrm{~T}_{2}, \mathrm{~T}_{3}\right)$ in Group 1 was compared with $\mathrm{T}_{0}$ of the controls, a significant ( $\mathrm{p}$ $<0.02$ ) decrease was found in the CFU/g of feces for Bifidobacterium spp. at $\mathrm{T}_{2}$, demonstrating that treatment with amoxicillin influenced the intestinal population of these microorganisms (Table 2).

In the examination of Lactobacillus spp. in Group 1 , the number of CFU/g of feces at $\mathrm{T}_{2}$ was smaller than that at $\mathrm{T}_{1}$, which was smaller than that at $\mathrm{T}_{3}(\mathrm{p}<$ $0.001)$. When each experimental time point $\left(T_{1}, T_{2}\right.$, $\mathrm{T}_{3}$ ) of Group 1 was compared with $\mathrm{T}_{0}$ of the controls, significantly fewer Lactobacillus spp. CFU/g of feces were found for time points $\mathrm{T}_{1}(\mathrm{p}=0.05)$ and $\mathrm{T}_{2}(\mathrm{p}<$ 0.01 , demonstrating that the infectious process affecting the respiratory tract and treatment with amoxicillin influenced the intestinal population of these microorganisms (Table 3).

Amoxicillin, however, did not prevent a quantitative recovery of Bacteroides spp. $\left(\mathrm{T}_{2}\right)$. Thirty days after the end of treatment $\left(\mathrm{T}_{3}\right)$, the concentrations of Bifidobacterium and Lactobacillus had recovered their normal values (Figure 1).

\section{Discussion}

The gastrointestinal ecosystem is an ample field for research and has long been the focus of interest of investigators. Although several studies have investigated the gastrointestinal microbiota [39-46], little information is available on the effect of some diseases and on the use of antimicrobials.

To help fill this gap, we investigated the influence of bacterial infections of the respiratory tract and of amoxicillin therapy on intestinal populations of the bacterial genera Bifidobacterium, Lactobacillus, and Bacteroides.
Several factors can influence the intestinal microbiota, including host age. Such changes, however, are more pronounced at birth, when the flora is established and the gastrointestinal tract is colonized with microorganisms ingested with food and acquired through contact with the environment $[17,47,48]$. Aging also promotes changes to the intestinal microbiota, significantly reducing the quantity of Bifidobacterium spp. and increasing the numbers of Lactobacillus spp., Clostridium perfringens, Escherichia coli, and Streptococcus spp. [17] Several authors have pointed out, however, that in the human adult phase the intestinal flora remains relatively stable, both qualitatively and quantitatively $[3,9,12,17,47,49,50]$. We found that age did not affect the qualitative or quantitative composition of the intestinal microbiota.

Another factor that has been suggested to influence this microbiota is diet $[2,6,39,46,51]$. Based on food consumption records and nutritional diagnosis, we did not find that diet had an influence on the intestinal microbiotic composition. However, all the individuals that were investigated lived in the same geographic location and had very similar diets.

Over the past years, a few studies have revealed the influence of certain inflammatory processes on the gastrointestinal microbiota. The relationship between rheumatoid arthritis and intestinal microbiota has been a focus of great interest for researchers, who have found patients with rheumatoid arthritis to harbor fecal floras significantly different from those of normal individuals [25,52,53].

A number of studies are currently being conducted on intestinal microbiota and allergic diseases, and reductions in microorganisms of the genera Lactobacillus, Bifidobacterium, and Bacteroides have been detected $[54,55]$. Alterations in the intestinal microbiota have also been observed in diarrhea episodes [48].

We also detected changes in the intestinal microbiota accompanying bacterial infections of the respiratory tract. This finding demonstrates that under conditions of infection and inflammation the ecological balance of the intestinal microbiota can be altered. 
Table 1. Mean counts (original scale) and means and standard deviations of log-transformed counts of Bacteroides spp. in a control group $\left(\mathrm{CG}\right.$; at time point $\left.\mathrm{T}_{0}\right)$ and in a group of patients with bacterial infection of the respiratory $\operatorname{tract}\left(\mathrm{G} 1\right.$; at three experimental time points: $\mathrm{T}_{1}$, before treatment; $\mathrm{T}_{2}$, at the end of treatment; $\mathrm{T}_{3}, 30$ days after treatment). Botucatu, SP, Brazil, 2002

\section{Bacteroides spp.}

\begin{tabular}{lcccc}
\hline & \multicolumn{2}{c}{$\mathbf{C G}(\mathbf{N}=\mathbf{2 0})$} & \multicolumn{2}{c}{$\mathbf{G 1}(\mathbf{N}=\mathbf{2 2})$} \\
\cline { 2 - 5 } & $\mathbf{T}_{\mathbf{0}}$ & $\mathbf{T}_{\mathbf{1}}$ & $\mathbf{T}_{\mathbf{2}}$ & $\mathbf{T}_{\mathbf{3}}$ \\
\hline Mean count & $7.17 \times 10^{10}$ & $1.81 \times 10^{10}$ & $4.09 \times 10^{10}$ & $3.87 \times 10^{10}$ \\
*Mean & 10.8557 & 10.2582 & 10.6121 & 10.5880 \\
*SD & 0.7138 & 1.0541 & 0.6265 & 0.6022 \\
\hline
\end{tabular}

*: mean values and standard deviations of log-transformed counts.

$\mathrm{N}$ : number of patients.

\begin{tabular}{lcccc}
\hline & Hypothesis & Calculated statistics & Significance level & Comment \\
\hline $\begin{array}{l}\text { Comparison of } \\
\mathrm{T}_{1}, \mathrm{~T}_{2} \text {, and } \mathrm{T}_{3}\end{array}$ & $\mathrm{~T}_{1}=\mathrm{T}_{2}=\mathrm{T}_{3}$ & $\chi^{2}=6.909$ & $\mathrm{p}<0.05$ & $\mathrm{~T}_{1}<\left(\mathrm{T}_{2}=\mathrm{T}_{3}\right)$ \\
Comparison of & $\mathrm{CG}=\mathrm{G} 1$ & $\mathrm{t}=2.19$ & $\mathrm{p}<0.05$ & $\mathrm{~T}_{0}>\mathrm{T}_{1}$ \\
CG and $\mathrm{G} 1$ & & $\mathrm{t}=1.18$ & $\mathrm{p}>0.10$ & $\mathrm{~T}_{0}=\mathrm{T}_{2}$ \\
& & $\mathrm{t}=1.32$ & $\mathrm{p}>0.10$ & $\mathrm{~T}_{0}=\mathrm{T}_{3}$ \\
\hline
\end{tabular}

Table 2. Mean counts (original scale) and means and standard deviations of log-transformed counts of Bifidobacterium spp. in a control group (CG; at time point $\mathrm{T}_{0}$ ) and in a group of patients with bacterial infection of the respiratory tract $\left(\mathrm{G} 1\right.$; at three experimental time points: $\mathrm{T}_{1}=$ before treatment, $\mathrm{T}_{2}=$ at the end of treatment, $\mathrm{T}_{3}=30$ days after treatment). Botucatu, SP, Brazil, 2002

\section{Bifidobacterium spp.}

\begin{tabular}{lcccc}
\hline & \multicolumn{2}{c}{$\mathbf{C G}(\mathbf{N}=\mathbf{2 0})$} & & $\mathbf{G 1}(\mathbf{N}=\mathbf{2 2})$ \\
\cline { 2 - 5 } & $\mathbf{T}_{\mathbf{0}}$ & $\mathbf{T}_{\mathbf{1}}$ & $\mathbf{T}_{\mathbf{2}}$ & $\mathbf{T}_{\mathbf{3}}$ \\
\hline Mean count & $8.41 \times 10^{9}$ & $4.37 \times 10^{9}$ & $1.85 \times 10^{9}$ & $4.44 \times 10^{9}$ \\
* Mean & 9.9250 & 9.6410 & 9.2676 & 9.7965 \\
*SD & 0.9551 & 0.7441 & 0.7962 & 0.7089 \\
\hline
\end{tabular}

*: mean values and standard deviations of log-transformed counts.

$\mathrm{N}$ : number of patients.

\begin{tabular}{lcccc}
\hline & Hypothesis & Calculated statistics & Significance level & Comment \\
\hline $\begin{array}{l}\text { Comparison of } \\
\mathrm{T}_{1}, \mathrm{~T}_{2} \text {, and } \mathrm{T}_{3}\end{array}$ & $\mathrm{~T}_{1}=\mathrm{T}_{2}=\mathrm{T}_{3}$ & $\chi^{2}=11.545$ & $\mathrm{p}<0.01$ & $\left(\mathrm{~T}_{1}=\mathrm{T}_{3}\right)>\mathrm{T}_{2}$ \\
Comparison of & $\mathrm{CG}=\mathrm{G} 1$ & $\mathrm{t}=1.08$ & $\mathrm{p}>0.10$ & $\mathrm{~T}_{0}=\mathrm{T}_{1}$ \\
CG and $\mathrm{G} 1$ & & $\mathrm{t}=2.43$ & $\mathrm{p}<0.02$ & $\mathrm{~T}_{0}>\mathrm{T}_{2}$ \\
& & $\mathrm{t}=0.50$ & $\mathrm{p}>0.50$ & $\mathrm{~T}_{0}=\mathrm{T}_{3}$ \\
\hline
\end{tabular}


Table 3. Mean counts (original scale) and means and standard deviations of log-transformed counts of Lactobacillus spp. for a control group $\left(\mathrm{CG}\right.$; at time point $\left.\mathrm{T}_{0}\right)$ and for a group of patients with bacterial infection of the respiratory tract $\left(\mathrm{G} 1\right.$; at three experimental time points: $\mathrm{T}_{1}$, before treatment; $\mathrm{T}_{2}$, at the end of treatment; $\mathrm{T}_{3}$, 30 days after treatment). Botucatu, SP, Brazil, 2002

\begin{tabular}{lcccc}
\hline & \multicolumn{4}{c}{ Lactobacillus spp. } \\
\cline { 2 - 5 } & \multicolumn{2}{c}{$\mathbf{C G}(\mathbf{N}=\mathbf{2 0})$} & \multicolumn{6}{c}{$\mathbf{G 1}(\mathbf{N}=\mathbf{2 2})$} \\
\hline \multirow{2}{*}{ Mean count } & $\mathbf{T}_{\mathbf{0}}$ & $\mathbf{T}_{\mathbf{1}}$ & $\mathbf{T}_{\mathbf{2}}$ & $\mathbf{T}_{\mathbf{3}}$ \\
* & $8.32 \times 10^{8}$ & $1.62 \times 10^{8}$ & $0.82 \times 10^{8}$ & $7.31 \times 10^{8}$ \\
* SD & 8.9199 & 8.2100 & 7.9146 & 8.8640 \\
& 0.9783 & 1.3747 & 1.3533 & 1.2934 \\
\hline
\end{tabular}

*: mean values and standard deviations of log-transformed counts.

$\mathrm{N}$ : number of patients.

\begin{tabular}{lcccc}
\hline & Hypothesis & Calculated statistics & Significance level & Comment \\
\cline { 2 - 5 } Comparison of & $\mathrm{T}_{1}=\mathrm{T}_{2}=\mathrm{T}_{3}$ & $\chi^{2}=20.727$ & $\mathrm{p}<0.001$ & $\mathrm{~T}_{2}<\mathrm{T}_{1}<\mathrm{T}_{3}$ \\
$\mathrm{~T}_{1}, \mathrm{~T}_{2}$, and $\mathrm{T}_{3}$ & $\mathrm{CG}=\mathrm{G} 1$ & $\mathrm{t}=1.96$ & $\mathrm{p}=0.05$ & $\mathrm{~T}_{0}>\mathrm{T}_{1}$ \\
Comparison of & $\mathrm{t}=2.79$ & $\mathrm{p}<0.01$ & $\mathrm{~T}_{0}>\mathrm{T}_{2}$ \\
CG and G1 & & $\mathrm{t}=0.16$ & $\mathrm{p}>0.50$ & $\mathrm{~T}_{0}=\mathrm{T}_{3}$ \\
\hline
\end{tabular}

Figure 1. Means of $\log _{10}$ of the number of Bacteroides spp., Bifidobacterium spp., and Lactobacillus spp. $\mathrm{CFU} / \mathrm{g}$ of feces in a control group (CG; at time point $\left.\mathrm{T}_{0}\right)$ and in a group of patients with bacterial infection of the

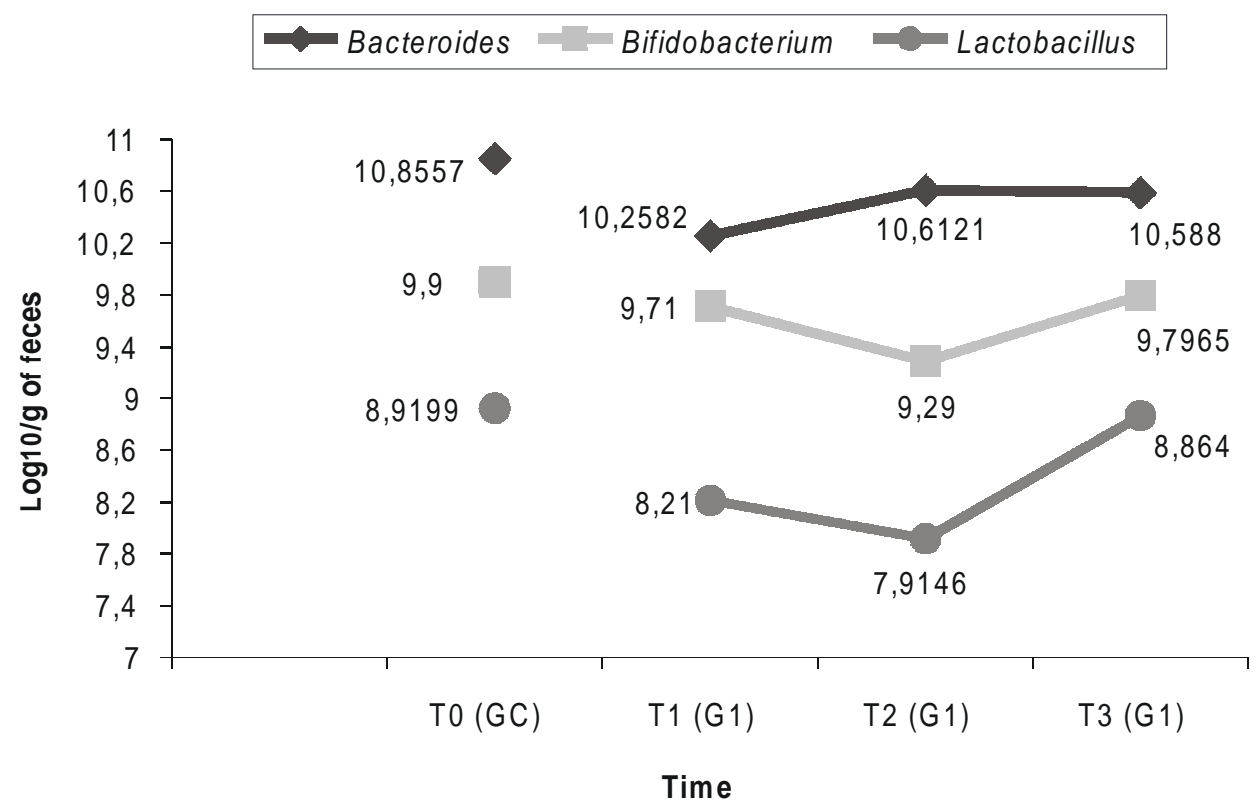


Another common cause of alteration in the gastrointestinal microbiota is the administration of antimicrobials, which can induce rapid and profound changes in the intestinal microflora $[36,48,56,57]$. The extent of these changes depends not only on the spectrum of action of the antimicrobial agent administered, but also on its degree of absorption, administration route, and possible enzymatic inactivation and/or ability to attach to water and to intestinal material [7].

During the past decade, several researchers have investigated the effects of various antimicrobial agents. Amoxicillin has been found to cause important alterations to the intestinal microbiota, affecting several groups of microorganisms both in patients and normal individuals. Changes include an increase in the number of enterobacteria and Bacteroides spp. [58], the emergence of resistant strains of enterobacteria [31,58,59], overgrowth of C. difficile, Candida spp. [58], Klebsiella spp., and Enterobacter spp. [60], a reduction in the anaerobic microflora [61], and a reduction in the number of bifidobacteria, lactobacilli, and clostridia [62].

In our study, the administration of amoxicillin led to a significant decrease in the CFU of Bifidobacterium spp. and Lactobacillus spp. /g of feces, though it did not prevent the recovery of Bacteroides spp. Thirty days after the end of treatment, the concentrations of all three microorganisms had returned to their normal values.

Identifying gastrointestinal microbiota imbalances caused by infectious processes and by the use of antimicrobials is thus quite important, as this microbiota has a decisive role in health maintenance. Any quantitative change in this group of microorganisms may have serious effects on the ecological balance of the intestinal microbiota, with detrimental consequences for the host.

\section{Conclusion}

The intestinal microbiota plays a central role in maintaining the host's health, and it can be adversely affected by bacterial infectious processes occurring in the respiratory tract, as revealed by the significant decrease in the CFU of Bacteroides spp. and Lactobacillus spp./g of feces. The use of amoxicillin also affected the intestinal microbiota, significantly decreasing the CFU of Bifidobacterium spp. and Lactobacillus spp./g of feces among these patients.

We expect that these results will encourage additional studies on the infectious processes in the Brazilian population, since the investigations available for comparison have been conducted in countries where socioeconomic and cultural conditions differ greatly from those found in Brazil, thus posing difficulties for comparative analyses. We suggest that there is a need for adopting nutritional measures that can minimize the negative effects of infectious processes and of the use of amoxicillin on the normal intestinal microbiota of patients.

\section{References}

1. Finegold S.M., Attebery H.R., Sutter V.L. Effect of diet on human fecal flora: comparison of Japanese and American diets. Am J Clin Nutr 1974;27:1456-69.

2. Rao A.V., Shiwnarain N., Koo M., Jenkins D.J.A. Effect of fiber-rich foods on the composition of intestinal microflora. Nutr Res 1994;14:523-35.

3. Berg R.D. The indigenous gastrointestinal microflora. Trends Microbiol 1996; 4: 430-5.

4. Norin K.E., Gustafsson B.E., Lindblad B.S., Midtvedt T. The establishment of some microflora associated biochemical characteristics in feces from children during the first years of life. Acta Paediatr Scand 1985; 74:207-12.

5. van der Waaij D. Colonization resistance of the digestive tract: Clinical consequences and implications. J Antimicrob Chemother 1982; 10:263-70.

6. Gibson G.R., Roberfroid M.B. Dietary modulation of the human colonic microflora: introducing the concept of prebiotics. J Nutr 1995; 125:1401-12.

7. Sullivan A., Edlund C., Nord C.E. Effect of antimicrobial agents on the ecological balance of human microflora. Lancet Infect Dis 2001;1:101-14.

8. Lidbeck A, Edlund C, Gustafsson J.A., et al. Impact of Lactobacillus acidophilus on the normal intestinal microflora after administration of two antimicrobial agents. Infection 1988; 16:329-36.

9. Salminen S., Bouley C., Boutron-Ruault M-C., et al. Functional food science and gastrointestinal physiology and function. Nutr Soc 1998;S148-71. 
10. Lidbeck A., Nord C.E. Lactobacilli and the normal human anaerobic microflora. Clin Infec Diseases 1993;16(Suppl 4): S181-7.

11. Hessle C., Hanson L.A., Wold A.E. Lactobacilli from human gastrointestinal mucosa are strong stimulators of IL-12 production. Clin Exp Immunol 1999; 116:276-82.

12. Simon G.L., Gorbach S.L. The human intestinal microflora. Dig Dis Sci 1986;31:147S-62S.

13. Isolauri E. Probiotics in human disease. Am J Clin Nutr 2001;73 (Suppl):S1142-6.

14. Lu L., Walker W.A. Pathologic and physiologic interactions of bacteria with the gastrointestinal epithelium. Am J Clin Nutr 2001; 73(Suppl): S1124-30.

15. Isolauri E., Sutas Y., Kankaanpaa P., et al. Probiotics: effects on immunity. Am J Clin Nutr 2001;73(Suppl 2):S444 - 50.

16. Vanderhoof J.A. Probiotics: future directions. Am J Clin Nutr 2001;73(Suppl): S1152- 5.

17. Mitsuoka T. Intestinal flora and aging. Nutr Rev 1992;50:438-46.

18. Guarner F. The colon as an organ: habitat of bacterial flora. Nutr Hosp 2002; 17 (Suppl 2):7-10.

19. Gibson G.R., Wang X. Regulatory effects of bifidobacteria on the growth of other colonic bacteria. J Appl Bacteriol 1994;77:412-20.

20. Macfarlane G.T., Gibson G.R. Co-utilization of polymerized carbon sources by Bacteroides ovatus grown in a twostage continuous culture system. Appl Environ Microbiol 1991;57:1-6.

21. Salyers A.A. Bacteroides of the human lower intestinal tract. Annu Rev Microbiol 1984;38:293-313.

22. Hopkins M.J., Macfarlane G.T. Changes in predominant bacterial populations in human faeces with age and with Clostridium difficile infection. J Med Microbiol 2002;51:448-54.

23. Macfarlane G.T., Gibson G.R., Drasar B.S., Cummings J.H. Metabolic significance of the gut microflora. In: Whitehead, editor. Gastrointestinal and Oesophageal Pathology. Edinburgh: Churchill Livingstone; 1995.

24. Nielsen O.H., Jorgensen S., Pedersen K., Justesen T. Microbiological evaluation of jejunal aspirates and faecal samples after oral administration of bifidobacteria and lactic acid bacteria. J Appl Bacteriol 1994;76:469-74.

25. Eerola E., Mottonen T., Hannonen P., et al. Intestinal flora in early rheumatoid arthritis. Br J Rhematol 1994;33:1030-8.

26. Peltonen R., Nenonen M., Helve T., et al. Fecal microbial flora and disease activity in rheumatoid arthritis during a vegan diet. Br J Rheutmatol 1997;36:64-8.

27. Hafstrom I., Ringertz B., Spangber A., et al. A vegan diet free of gluten improves the signs and symptoms of rheumatoid arthritis: the effects on arthritis correlate with a reduction in antibodies to food antigens. Rheumatology 2001;40:1175-79.
28. Toivanen P., Eerola E. A vegan diet changes the intestinal flora. Rheumatology 2002;41:950-1.

29. Isolauri E. Intestinal involvement in atopic disease. J Royal Soc Med 1997;90 (Suppl 30):15-20.

30. Kalliomäki M., Kirjavainen P., Eerola E., et al. Distinct patterns of neonatal gut microflora in infants in whom atopy was and was not developing. J Allergy Clin Immunol 2001; 107:129-34.

31. Floor M., van Akkeren F., Rozenberg-Arska M., et al. Effect of loracarbef and amoxicillin on the oropharyngeal and intestinal microflora of patients with bronchitis. Scand J Infect Dis 1994;26:191-7.

32. Jacobs M.R. Emergence of antibiotic resistance in upper and lower respiratory tract infections. Am J Manag Care 1999;5: S651- 61.

33. Philipp S.T., Szarfa S.C., Latterga A.R. Virtual Nutri software, Version 1.0 for Windows. São Paulo: Departamento de Nutrição da Faculdade de Saúde Pública. Universidade de São Paulo; 1996.

34. WHO. Report of a WHO Expert Committee. Physical status: the use and interpretation of anthropometry. WHO Technical Report Series, n⿳ 854, 1995.

35. Sutter V.L., Citron D.M., Finegold S.M., Brichnell K.S. Wadsworth anaerobic bacteriology manual. Department of Continuing Education in Health Sciences, University Extension, and the School of Medicine, UCLA. California: C.V. Mosby Company, 1972.

36. Nordenvall B., Hallberg D., Larsson L., Nord C.E. The effect of clindamycin on the intestinal flora in patients with enteric hyperoxaluria. Scand J Gastroenterol 1983; $18: 177-81$.

37. Barza M., Giuliano M., Jacobus N.V., Gorbach S.L. Effect of broad-spectrum parenteral antibiotics on 'colonization resistance' of intestinal microflora of humans. Antimicrobial agents and Chemotherapy 1987;31:723-27.

38. Curi P.R.. Metodologia e análise da pesquisa em ciências biológicas. $2^{\text {nd }}$ ed. Botucatu: Tipomic; 1998.

39. Finegold S.M., Sutter V.L. Fecal flora in different populations, with special reference to diet. Am J Clin Nutr 1978; 31:S116-22.

40. Moore W.E.C., Holdeman L.V. Human fecal flora: the normal flora of 20 Japanese-Hawaiians. Appl Microbiol 1974;27:961-79.

41. Luckey T.D. Introduction to intestinal microecology. Am J Clin Nutr 1972;25:1292-4.

42. Midtvedt T. Microbial acid transformation. Am J Clin Nutr 1974;27:1341-7.

43. Macfarlane G.T., Cummings J.H., Allison C. Protein degradation by human intestinal bacteria. J Gen Microbiol 1986; 132:1647-56. 
44. Macfarlane G.T., Allison C., Gibson S.A.W., Cummings J.H. Contribution of the microflora to proteolysis in the human large intestine. J Appl Bacteriol 1988;64:37-46.

45. Beerens H. Detection of bifidobacteria by using propionic acid as a selective agent. Appl Environ Microbiol 1991;57:2418-9.

46. Speck R.S., Calloway D.H., Hadley W.K. Human fecal flora under controlled diet intake. Am J Clin Nutr 1970;23:1488-94.

47. Broido P.W., Gorbach S.L., Nyhus L.M. Microflora of the gastrointestinal tract and the surgical malabsorption syndromes. Surg Gynecol Obstet 1972; 135:449-60.

48. Salminen S., Isolauri E., Onnela T. Gut flora in normal and disordered states. Chemotherapy 1995;41(Suppl 1):515.

49. Roberfroid M.B., Bornet F., Bouley C., Cummings J.H. Colonic microflora: nutrition and health. Nutr Rev 1995;53:127-30.

50. Edwards C. Interactions between nutrition and the intestinal microflora. Proc Nutr Soc 1993;52:375-82.

51. Cummings J.H., Hill M.J., Jenkins D.J.A., et al. Changes in fecal composition and colonic function due to cereal fiber. Am J Clin Nutr 1976;29:1468-73.

52. Shinebaun R., Neumann V.C., Cooke E.M., Wright V. Comparison on faecal flora in patients with rheumatoid arthritis and controls. Br J Rheumatol 1987;26:329-33.

53. Malin M., Verronen P., Mykkanen H., et al. Increased bacterial urease activity in faeces in juvenile chronic arthritis: evidence of altered intestinal microflora? $\mathrm{Br} \mathrm{J}$ Rheumatol 1996;35:689-94.

54. Björkstén B., Naaber P., Sepp E., Mikelsaar M. The intestinal microflora in allergic Estonian and Swedish 2-year-old children. Clin Exp Allergy 1999;29:342-6.

55. Watanabe S., Narisawa Y., Arase S., et al. Differences in fecal microflora between patients with atopic dermatitis and health control subjects. J Allergy Clin Immunol 2003; 111:587-91.

56. Mackowiak P.A. The normal microbial flora. N Engl J Med 1982;307: 83-93.

57. Gorbach, S.L., Spaknebel G., Weinstein L., et al. Studies of intestinal microflora. VIII. Effect of Lincomycin on the microbial population of the human intestine. J Infect Dis 1969;120:298-304.

58. Christensson B., Nilsson-Ehle I., Ljungberg B., et al. A randomized multicenter trial to compare the influence of cefaclor and amoxycillin on the colonization resistance of the digestive tract in patient with lower respiratory tract infections. Infection 1991;4:208-15.

59. Edlund C., Stark C., Nord C.E. The relationship between an increase in â-lactamase activity after oral administration of three new cephalosporins and protection against intestinal ecological disturbances. J Antimicrob Chemother 1994;34:127-38.
60. Brismar B., Edlund C., Nord C.E. Impact of cefpodoxime proxetil and amoxicillin on the normal oral and intestinal microflora. Eur J Clin Microbiol Infect Dis 1993; 12:714-9.

61. Stark C.A., Adamsson I., Edlund C., et al. Effects of omeprazole and amoxycillin on the human oral and gastrointestinal microflora in patients with Helicobacter pylori infection. J Antimicrob Chemother 1996;38:927-39.

62. Lode H., von der Höh N., Ziege S., et al. Ecological effects of linezolid versus amoxicillin/clavulanic acid on the normal intestinal microflora. Scand J Infect Dis 2001;33:899-903. 